\title{
Does body posture affect the incidence and mechanism of gastro-oesophageal reflux?
}

\author{
N Freidin, R K Mittal, R W McCallum
}

\begin{abstract}
We studied eight patients with gastro-oesophageal reflux disease to compare the frequency and mechanism of reflux in the upright and supine positions. Simultaneous oesophageal manometry and $\mathrm{pH}$ studies were performed on two separate days in each subject in the fasting and postprandial periods. The frequency of reflux tended to be higher in the upright position. The most prevalent mechanism of reflux in either position was transient relaxation of the lower oesophageal sphincter. The frequency of transient lower oesophageal sphincter relaxation was higher in the upright than in the supine position. There was no difference in the total reflux time, acid clearance time, and number of reflux episodes lasting longer than five minutes in the two positions. We suggest that daytime reflux (upright) may be as important as night time (supine) reflux in the pathogenesis of reflux oesophagitis and needs to be considered when treating patients with reflux disease.
\end{abstract}

Ambulatory oesophageal $\mathrm{pH}$ recordings show that gastro-oesophageal reflux occurs in the upright as well as in the supine position. The supine position is conventionally thought to be more conducive to reflux because of the opposing effect of gravitational forces on reflux in the upright position. ${ }^{1}$ Recent studies suggest, however, that gastro-oesophageal reflux may be more prevalent in the upright than in the supine position. ${ }^{2}$ In normal subjects and patients with reflux disease, transient lower oesophageal sphincter relaxation is the major mechanism of reflux in the supine position..$^{3-5}$ There is, however, no information about the mechanism of reflux in the upright position in humans. We were specifically interested in the changes in intragastric pressure at the time of gastrooesophageal reflux that might facilitate movement of gastric contents (acid) into the oesophagus in the upright position.

\section{Methods}

Department of Internal Medicine, University of Virginia, Charlottesville, Virginia, USA

N Freidin

R K Mittal

R W McCallum

Correspondence to:

Dr R K Mittal, Box 145,

University of Virginia Health

Sciences Center,

Charlottesville, Virginia 22908, USA.

Accepted for publication

4 April 1990

Simultaneous oesophageal $\mathrm{pH}$ and oesophageal manometry recordings were performed in eight patients with gastro-oesophageal reflux disease. There were four men and four women with a mean age of $43 \cdot 3$ years (range 23-64 years). All of these patients had experienced daily heartburn for more than six months. Four had endoscopic evidence of oesophagitis in the form of erosion and ulceration of the oesophagus. The other four had normal oesophageal mucosa, but had a positive Bernstein test. A Bernstein test was interpreted as positive if the patient's symptom of heartburn was reproduced within 10 minutes of onset of infusion of $\mathrm{N} / 10 \mathrm{HCl}$ into the oesophagus. All of the patients showed peristaltic waves of normal amplitude and duration during clinical manometry. The protocol of this study was approved by the Human Investigations Committee of the University of Virginia and informed consent was obtained from each patient before the study.

\section{MANOMETRIC TECHNIQUE}

Studies were performed in the morning after an overnight fast. Subjects refrained from smoking and drinking alcohol for at least 24 hours before the study. Antisecretory and prokinetic drugs were stopped for 48 hours before the study. A motility catheter with a $6 \mathrm{~cm}$ long Dent sleeve device and an attached micro $\mathrm{pH}$ electrode (Londonderry, NH) was passed transnasally. This assembly was positioned so that the oesophageal $\mathrm{pH}$ was recorded at $5 \mathrm{~cm}$ above the lower oesophageal sphincter. Pressures were recorded simultaneously from the gastric fundus, lower oesophageal sphincter, oesophageal body (at sites 2,7 , and $12 \mathrm{~cm}$ proximal to the lower oesophageal sphincter), and pharynx. The pharyngeal and oesophageal pressures were monitored by means of the water filled catheters rather than the continuously perfused method in order to minimise water loading of the subjects. The lower oesophageal sphincter and gastric pressures were measured with a continuously perfused $(0.6 \mathrm{ml} / \mathrm{minute})$ Dent sleeve and side hole located $2 \mathrm{~cm}$ below the sleeve respectively. The $\mathrm{pH}$ and manometric signals were recorded simultaneously on an eight channel recorder (R 612, Sensormedics, Anaheim, California). Studies were performed on two successive days in each patient. Four patients had studies performed in the horizontal position on day one and the other four in the upright position on day one. During the horizontal study the patients sat up only for the meal.

The gastro-oesophageal pressure gradient in the horizontal and vertical positions was calculated by the difference in the end expiratory pressure recorded by the side hole located above the sleeve device as it was pulled from the
Comparison of data in the horizontal and vertical positions during fasting. Values, mean (SEM)

\begin{tabular}{|c|c|c|c|c|}
\hline Position & $G E R$ & TLESR & $\begin{array}{l}\text { Total reflux } \\
\text { time }(\%)\end{array}$ & $\begin{array}{l}\text { Acid clearance } \\
\text { time }(\mathrm{sec})\end{array}$ \\
\hline $\begin{array}{l}\text { Horizontal } \\
\text { Vertical }\end{array}$ & $\begin{array}{l}1 \cdot 1(0 \cdot 6) \\
0 \cdot 4(0 \cdot 2)\end{array}$ & $\begin{array}{l}3 \cdot 7(0 \cdot 7) \\
5 \cdot 7(1 \cdot 3)\end{array}$ & $\begin{array}{l}1 \cdot 0(0 \cdot 6) \\
0 \cdot 1(0 \cdot 1)\end{array}$ & $\begin{array}{r}14 \cdot 8(7 \cdot 6) \\
4 \cdot 4(4 \cdot 1)\end{array}$ \\
\hline
\end{tabular}

GER = gastro-oesophageal reflux; TLESR = transient lower oesophageal sphincter relaxation. 
stomach into the oesophagus. After one hour of recording in the fasting state, patients ate a standard $1000 \mathrm{kcal}$ meal. The meal contained $40 \mathrm{~g}$ carbohydrate, $40 \mathrm{mg}$ protein, and $20 \mathrm{mg}$ fat. Recordings were obtained continuously for an additional two and a half hours after the meal.

\section{DATA ANALYSIS}

A gastro-oesophageal reflux event was defined as an abrupt $\mathrm{pH}$ drop of at least 1 unit. Transient lower oesophageal sphincter relaxation was defined as an abrupt fall in lower oesophageal sphincter pressure (unassociated with swallow) of at least $5 \mathrm{mmHg}$. Swallowing was monitored by recording pharyngeal contraction through a manometric side hole positioned in the pharynx. The lower oesophageal sphincter relaxation beginning at least three seconds before the onset of pharyngeal contraction was called a transient lower oesophageal sphincter relaxation. ${ }^{6}$ The fall in sphincter pressure had to be longer than five seconds. Transient sphincter relaxations that resulted in a residual pressure of less than $4 \mathrm{mmHg}$ (complete transient lower oesophageal sphincter relaxation) were counted. Free reflux was defined when it coincided with atonic lower oesophageal sphincter (pressure $<4 \mathrm{mmHg}$ ) and no change in gastric pressure occurred at the time of the reflux event. Stress reflux was divided into type 1 and type 2 . It was labelled type 1 when the resting lower oesophageal sphincter pressure was greater than $5 \mathrm{mmHg}$ and there was a transient increase in intragastric pressure of greater than $5 \mathrm{mmHg}$ at the time of reflux. Type 2 was defined when a transient increase in intragastric pressure occurred during transient sphincter relaxation and resulted in a reflux event.

The increase in intragastric pressure was thought to be causally related to stress reflux only if it preceded the reflux event by less than five seconds and was greater than $5 \mathrm{mmHg}$ in amplitude. The five second period was arbitrarily chosen to account for the time taken by the acid to travel from the stomach to the $\mathrm{pH}$ probe located $5 \mathrm{~cm}$ above the lower oesophageal sphincter. The amplitude of $5 \mathrm{mmHg}$ for gastric pressure was again arbitrarily selected because transient lower oesophageal sphincter pressure was defined as a fall in pressure to within $4 \mathrm{mmHg}$, and we reasoned that the gastric pressure had to be at least greater than that of the lower oesophageal sphincter for reflux to occur.

The time interval between the drop in lower oesophageal sphincter pressure to $4 \mathrm{mmHg}$ (during transient sphincter relaxations) and the reflux event was measured in the horizontal and vertical position (transient sphincter relaxations related to stress type 2 reflux events were excluded from this analysis). The end expiratory gastro-oesophageal pressure gradient was determined in the supine position for each subject as the difference in pressure recorded by a side hole as it was pulled from the stomach into the oesophagus.

The recordings obtained in the horizontal and vertical positions during fasting and postprandially were analysed for: frequency of reflux events ( $\mathrm{pH}$ drop of more than 1 unit), the percentage time that the oesophageal $\mathrm{pH}$ was below 4 (total reflux time), clearance time (total $\mathrm{pH}$ time below 4 divided by the number of reflux events resulting in $\mathrm{pH}$ below 4), the longest reflux episode (measured in seconds, with oesophageal $\mathrm{pH}$ below 4) and the number of reflux episodes longer than five minutes. For the purpose of total reflux time and acid clearance time, the oesophageal $\mathrm{pH}$ value of 4 was selected because only a pH less than 4 is considered to be injurious to the oesophageal mucosa. The number of transient lower oesophageal sphincter relaxations as well as the number of reflux events induced by transient relaxations, free, or stress mechanisms were determined in each position. The percentage of transient lower oesophageal sphincter relaxations associated with acid reflux were also determined in each position. The resting lower oesophageal sphincter pressure was measured as the maximal end expiratory pressure for each minute of recording and was averaged for the fasting and postprandial periods. Paired Student's $t$ tests and $\chi^{2}$ tests were used as appropriate to assess statistical significance. Data are presented as mean (SEM).

\section{Results}

The resting lower oesophageal pressure was significantly lower in the vertical than in the horizontal position - mean (SEM) 14.4 (1.5) and $18.1(1.9)$ respectively $(\mathrm{p}<0.05)$. The gastrooesophageal pressure gradient in the supine position was $3.4(0.8) \mathrm{mmHg}$.

Frequency of gastro-oesophageal reflux, transient lower oesophageal reflux, percentage of transient reflux associated with gastrooesophageal reflux, total reflux time, and acid clearance time were not different in the horizontal and vertical positions during fasting (Table). The following describes data from the postprandial period. There was a tendency for the frequency of reflux to be higher in the vertical than the horizontal position: 10.3 mean (SEM) (1.5) and 6.2 (1.7) per subject respectively $(0.05<\mathrm{p}<0.1$ (Fig 1). Total reflux time was not significantly greater in the vertical than in the horizontal position $(18.9(5.4) \%$ and 9.4 (3.7)\% respectively) (Fig 1). The acid clearance time in the two positions was not different (Fig 1). No difference was found in the duration of the longest reflux event and in the number of reflux episodes lasting longer than five minutes in the two positions.

The transient lower oesophageal reflux frequency was higher in the vertical than in the horizontal position - mean (SEM) $16 \cdot 0(2 \cdot 3)$ and $9 \cdot 7(1 \cdot 2)(\mathrm{p}<0 \cdot 01)$ respectively (Fig 2$)$. The reflux frequency during transient lower oesophageal relaxation was also higher in the vertical position $(7 \cdot 3(1 \cdot 3) v 4 \cdot 0(0 \cdot 9))$. However, the percentage of transient lower oesophageal relaxations associated with reflux were comparable in the two positions (horizontal, 61\% $v$ vertical, $66 \%$ ). The number of reflux events induced by stress and free mechanisms was the same in either position (horizontal: $2 \cdot 0(0 \cdot 9)$ and vertical $2 \cdot 8(0 \cdot 8))$.

In the horizontal position, $20 \%$ of the reflux events occurring during transient lower 

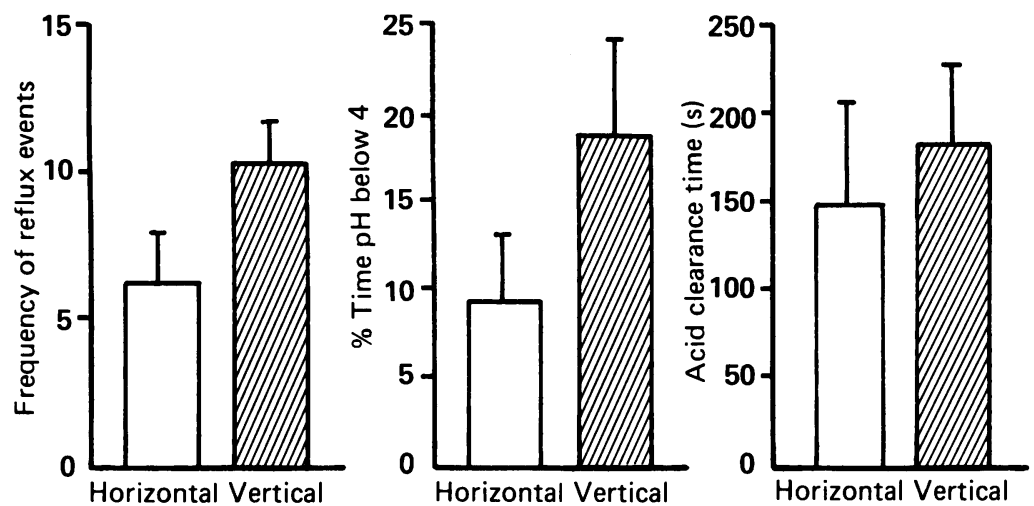

Figure 2: Frequency of reflux events, percentage of time oesophageal $\mathrm{pH}$ below 4, and acid clearance time were similar in the horizontal and vertical positions.
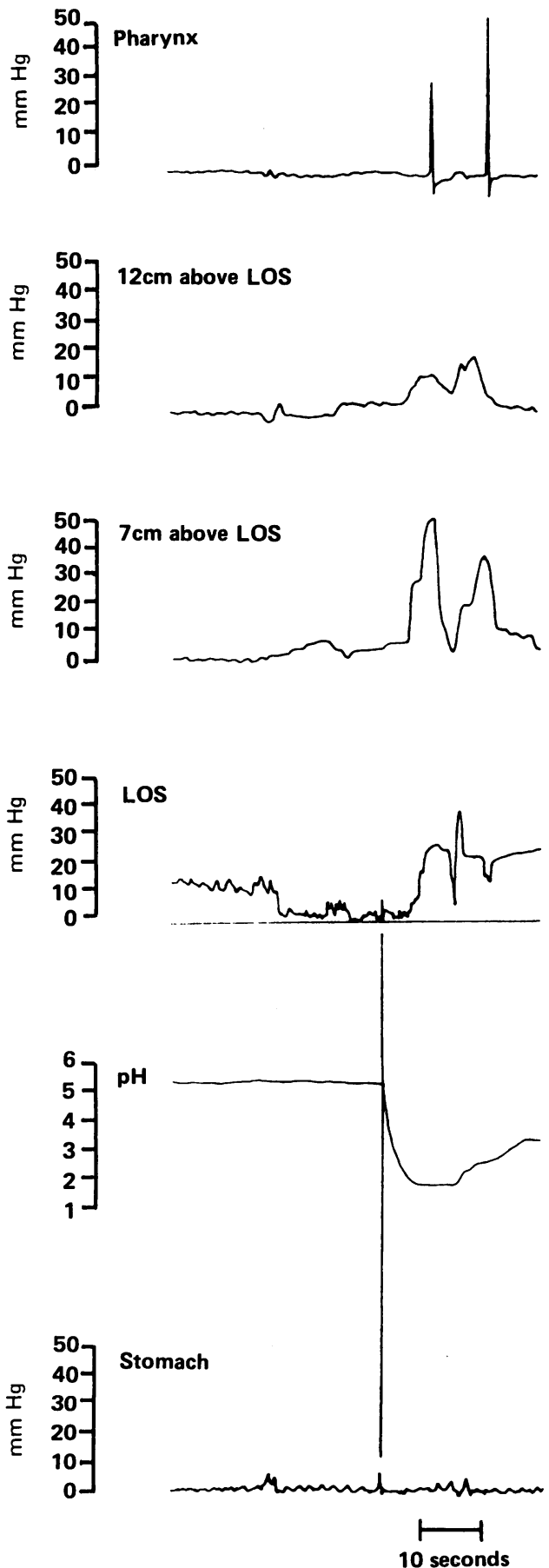

Figure 3: Mechanism of acid reflux. Acid reflux occurs during transient relaxation of the lower oesophageal sphincter (LOS). Note an increase in intragastric pressure at the movement of drop in oesophageal $\mathrm{pH}$. The increase in gastric pressure was seen at times other than transient LOS relaxation but these increases were not associated with acid reflux. oesophageal relaxations were associated with an increase in intragastric pressure (stress type 2 reflux) (Fig 3). In the vertical position, $24 \%$ of the reflux events during transient relaxations were type 2 . The time interval between a residual lower oesophageal sphincter pressure of $4 \mathrm{mmHg}$ during transient lower oesophageal reflux and the reflux event was the same in the two positions (horizontal: $5 \cdot 7(0.9)$ seconds, vertical: $5 \cdot 7(0 \cdot 6)$ seconds.

\section{Discussion}

The pressure gradient between the stomach and oesophagus may be considered as a driving force and lower oesophageal sphincter pressure as the barrier to acid reflux. A number of studies show that the most common mechanism of acid reflux in the supine position is a complete transient lower oesophageal sphincter relaxation that results in a lower oesophageal sphincter pressure of less than $5 \mathrm{mmHg}{ }^{3-5}$ The gastro-oesophageal pressure gradient of 3 to $5 \mathrm{mmHg}$ in the resting state may be an explanation for the observation that a lower oesophageal sphincter pressure of $5 \mathrm{mmHg}$ or more is an effective antireflux barrier. We found that in the upright position complete transient lower oesophageal sphincter relaxation is also the major mechanism of gastrooesophageal reflux. In the supine position, no change in intragastric pressure has been reported to occur during most reflux events. We expected that the increase in intragastric pressure would be critical to the occurrence of reflux in the vertical position because acid is traversing into the stomach from the oesophagus against gravity. An increase in intragastric pressure during transient lower oesophageal sphincter relaxation may be thought of as an additional driving force for acid reflux. We found this to be present, however, during only $24 \%$ of instances. There was no difference in the frequency of stress type 2 reflux between the vertical and supine positions.

We reasoned that the time between the lower oesophageal sphincter relaxation and the actual occurrence of reflux might provide some clue to the driving force for reflux. During most stress type 2 reflux events we found that there was a very close relation between the occurrence of intragastric pressure and the acid reflux event. In the absence of intragastric pressure increase, there was a time lag between lower oesophageal sphincter pressure drop to $<4 \mathrm{mmHg}$ and an acid reflux event of five to seven seconds in the horizontal as well as vertical position. It is surprising, because in the absence of an additional driving force in the vertical position (against gravitational force) the time for acid to travel from the stomach to the $\mathrm{pH}$ probe would be expected to be greater. Our data suggest that there are factors other than the pressure gradient (as observed by manometry) that may be operative in driving reflux. One possibility is that the movement of acid from the stomach into the oesophagus in the presence of a lower oesophageal sphincter pressure $<4 \mathrm{mmHg}$ occurs by a diffusion mechanism rather than a pressure gradient mechanism.

We observed that the frequency of transient 
lower oesophageal sphincter relaxation is higher in the vertical than in the supine position. Cox and Martin observed similar posture related differences in the frequency of transient sphincter relaxation in dogs. ${ }^{7}$ Furthermore, Martin et al found that frequency of transient sphincter relaxations can be diminished by denervation of fundus of the stomach. ${ }^{8-10}$ It is possible that transient sphincter relaxation results from excitation of mechanoreceptors located in the proximal stomach. ${ }^{6-8}$ Since the air accumulates in the fundus of the stomach in the vertical position, it is likely to stimulate these mechanoreceptors. On the other hand, ingested air is likely to be more uniformly distributed in the stomach in the supine position, therefore causing less excitation of the mechanoreceptors located in the fundus of the stomach.

Johnson $e t a l^{1}$ showed the beneficial effect of raising the head of the bed in patients with excessive recumbent oesophageal acid exposure. Hamilton et $a l^{11}$ showed only a marginal benefit of this, however, in the management of reflux oesophagitis, but they did not monitor the sleep stages. As reflux can only occur during awake periods interspersed among sleep stages, ${ }^{312}$ different sleep patterns cannot be ruled out as a factor in the differences they found. The only study that compared the two positions in a state of wakefulness was performed by Habibulla et $a l .{ }^{13}$ They found that the vertical position was ineffective in preventing reflux events. On the contrary, the frequency of reflux episodes was significantly increased in this position. Furthermore, there was no difference between either position in the percentage of time during which the oesophageal $\mathrm{pH}$ was below 4 . In contrast to our study, however, they found a significantly shorter mean clearance time in the vertical position. DeCaestecker et $a l^{2}$ recently showed that the oesophageal acid exposure and clearance times in the vertical position correlated better with the severity of oesophagitis than those of nocturnal reflux events in the horizontal position. Contrary to expectation, our study shows that reflux occurs more frequently in the vertical position in patients with reflux disease. We also observed that other parameters of reflux such as the number of reflux episodes, acid clearance time, total reflux time, and longest reflux episodes were no different in the vertical and horizontal positions. It is possible that there is a group of patients studied by Johnson $e t$ al that suffers reflux more in the supine position and in whom the vertical position would be helpful in management. We think, however, that our group represents the majority of the patients observed routinely in clinical practice. Fifty per cent of our patients had evidence of endoscopic oesophagitis. Gastro-oesophageal reflux at night (supine position) is considered to be more important in the pathogenesis of oesophagitis. We suggest, however, that daytime reflux (in the upright position) is equally important and should be considered when tailoring treatment for reflux oesophagitis.

1 Johnson LF, DeMeester TR. Evaluation of elevation of the head of the bed, bethanechol and antacid foam tablets on gastroesophageal reflux. Dig Dis Sci 1981; 6: 673-80.

2 DeCaestecker JS, Blackwell JN, Pryde A, Herdin RC. Daytime gastroesophageal reflux is important in esophagitis. Gut 1987; $28: 519-26$

3 Dent J, Dodds WJ, Friedman RH, Sekziguchi T, Hogan WJ, Arndorfer RC. Mechanism of gastroesophageal reflux in recumbent asymptomatic human subjects. $\mathcal{F}$ Clin Invest 1980; 65: 256-7

4 Dodds WJ, Dent J, Hogan WJ, et al. Mechanism of gastroesophageal reflux in patients with reflux esophagitis. $N E n g l$ f Med 1982; 307: 1547-51.

5 Mittal RK, McCallum RW. Characteristics and frequency of transient lower esophageal sphincter relaxation in patients
with reflux esophagitis. Gastroenterology 1988; 95: 593-9.

6 Mittal RK, McCallum RW. Characteristics of transient lower esophageal sphincter relaxation in humans. Am $\mathcal{F}$ Physiol 1987; 252: G636-G4

7 Cox MR, Martin CJ, Dent J. Postural suppression of transient lower esophageal sphincter relaxation is not mediated by gastric fluid receptor in the dog. Gastroenterology 1987; 92: 1357.

8 Martin CJ, Franzi SJ, Dent J, Cox MR. The effect of sham fundoplication on transient lower esophageal sphincter relaxation. Gastroenterology 1988; 94: A285

9 Holloway RH, Hongo M, Berger K, McCallum RW. Gastric distention: a mechanism for postprandial gastroesophageal reflux. Gastroenterology 1985; 89: 779-84.

10 Franzi SJ, Martin CJ, Dent J, Cox MR. Localization of a trigger for transient lower esophageal sphincter relaxations trigger for transient lower esophageal sphincter relaxations
(TLESRs) in the day. [Abstract] Gastroenterology 1988; 95: 865 .

11 Hamilton JW, Boisen RJ, Yamamoto DT, Wagner JL, Reichelderfer $M$. Sleeping on a wedge diminishes exposure of the esophagus to refluxed acid. Dig Dis Sci 1988; 33: 518-22.

12 Freidin N, Fisher MJ, Taylor W, Boyd D, McCallum RW, Mittal RK. Pattern of sleep and nocturnal acid reflux in normal subjects and gastroesophageal reflux patients. Gastroenterology (in press)

13 Habibulla KS, Ammann JF, Callis JL. Effect of posture in hiatus hernia as studied by oesophageal $\mathrm{pH}$ measurement. Thorax 1971; 26: 689-95. 